\title{
Effects of preharvest, harvest and postharvest factors on the quality of pear (cv. 'Rocha') stored under controlled atmosphere conditions
}

\author{
Andrea C. Galvis-Sánchez, Susana C. Fonseca, Alcina M.M.B. Morais, \\ F. Xavier Malcata * \\ Escola Superior de Biotecnologia, Universidade Católica Portuguesa, Rua Dr. António Bernardino de Almeida, P-4200-072 Porto, Portugal
}

Keywords: Storage; Gas composition; Date of harvest; Growing location; Firmness; Colour; Modelling

\begin{abstract}
Pears (cv. 'Rocha') grown at two locations and picked up at various times during the harvest season were assessed for firmness and colour, following 9 mo of storage under air or under controlled atmosphere conditions. A second-order polynomial was able to accurately fit the effect of time of harvest on pear's quality, in an essentially empirical modelling effort; the best estimates of the parameters therein depend on the growing location, as well as on the atmosphere gas composition prevailing during storage.
\end{abstract}

\section{Introduction}

The fresh pear market faces two major problems: one such problem is caused by unfavorable handling and storage practices-harvest at the wrong stage of maturity, refrigeration at excessively slow rates and inadequate temperatures of storage (Klahre et al., 1987); the second problem derives from the intrinsic variability in terms of fruit quality, which is determined primarily by specific varietal characteristics, and by environmental conditions prevailing during the growing season (Hansen \& Mellenthin, 1979; Saltveit, 2003).

Controlled atmospheres (CA) have been applied to fresh pears with the goal of providing fruits throughout the marketing season with guaranteed uniform characteristics (Allen, 1939; Kupferman, 1994); several studies encompassing CA storage have assessed the main factors that may influence loss of pear quality after said storage (Avelar, 1984; Kupferman, 1987). The physiological stage of the fruit at harvest, commonly referred to as harvest maturity, was claimed (Meheriuk, Evans, Talley, \& Kupferman, 1988) to be a limiting factor in CA storage; the response of pears to specific CA con-

${ }^{*}$ Corresponding author. Tel.: +351-22-5580004; fax: +351-225090351.

E-mail address: xmalcata@esb.ucp.pt (F.X. Malcata). ditions depends not only on the pear variety and cultivar, but also on the CA regime applied (Hansen \& Mellenthin, 1962; Hansen, 1999).

In the case of 'Rocha' variety, it is known (GalvisSánchez, Fonseca, Morais, \& Malcata, 2003) that it possesses an excellent storage capacity, which allows its preservation for up to 9 mo under controlled conditions; however, the sensorial quality of that variety is influenced by such storage factors as duration of storage and concentration of overhead $\mathrm{O}_{2}$.

This research effort was designed and conducted so as to determine the response of 'Rocha' pears, harvested at several degrees of maturity and grown in two different locations, to selected CA storage conditions.

\section{Materials and methods}

\section{Plant material and experimental design}

Experimental studies were conducted with pears harvested in August 1999, in the western region of Portugal at two different locations (Sobrena-location 1, and Clone-location 2), at three harvest dates: August 10th, 17th and 24th (i.e. Pick 1, 2 and 3 for location (1); and August 17th, 24th and 31st (i.e. Pick 1, 2 and 3 for location (2). Pears were immediately stored under 
one of two CA conditions: $2 \%(\mathrm{v} / \mathrm{v}) \mathrm{O}_{2}+0.5 \%(\mathrm{v} / \mathrm{v}) \mathrm{CO}_{2}$, and $2.5 \%(\mathrm{v} / \mathrm{v}) \mathrm{O}_{2}+0.7 \%(\mathrm{v} / \mathrm{v}) \mathrm{CO}_{2}$. Two experimental chambers (with an individual capacity of $225 \mathrm{~kg}$ ) were employed for each storage atmosphere; the temperature therein was kept at $0-0.5^{\circ} \mathrm{C}$, and the relative humidity at $90-95 \%$; the error in the target overhead gaseous concentration was $\pm 0.1 \%(\mathrm{v} / \mathrm{v})$. Pears stored in air were used as control. After 4, 6 and 9 mo of storage, pears selected at random were removed from the chamber at the appropriate storage condition, and were allowed to ripen in air at room temperature $\left(19-20^{\circ} \mathrm{C}\right)$. Pears were then randomly selected (for each previous storage condition) and evaluated in terms of firmness and colour, by 1,4 and $7 \mathrm{~d}$ in the case of location 1 , and by 2,5 and $8 \mathrm{~d}$ in the case of location 2 .

\section{Firmness and colour evaluations}

Firmness assessment was performed with an universal testing machine, model 4501 (from Instron, Canton MA, USA), equipped with an $8 \mathrm{~mm}$-probe that was programmed to penetrate $5 \mathrm{~mm}$ in a normal direction, at a crosshead speed of $10 \mathrm{~mm} / \mathrm{min}$, using a $100 \mathrm{~N}$ load cell. Two sets of 10 pears were used as replicates. Firmness results were expressed as the maximum force (N) to puncture the equatorial surface of a whole skinless pear. The colour of the flesh was assessed with a (hand-held) tristimulus reflectance colorimeter, model
CR-300 (from Minolta, Ramsey IL, USA); colour was recorded using a Hunter's $L^{*} a^{*} b^{*}$ system. Two sets of 10 pears each were again employed as replicates. The colour parameters selected for further considerations were $a^{*}$ and $b^{*}$, because these were the best indicators of the influence of the processing factors tested. Despite the classical representation of colour as hue angle, the axial coordinates $a^{*}$ and $b^{*}$ were preferred in view of the higher informational content of the latter approacheven at the expense of a higher number of figures.

\section{Statistical analysis and model parameter estimation}

The firmness and colour results were subject to analysis of variance (ANOVA), and Duncan's multiple range test was applied to detect significant differences. The use of ANOVA will be valid if the experimental errors are independent and normally distributed, and if they possess a constant variance. In order to validate this assumption, the original experimental data of firmness had to be previously transformed using a logarithmic function.

The influence of storage time $\left(X_{1}\right)$, ripening time $\left(X_{2}\right)$, concentrations of oxygen $\left(X_{3}\right)$ and carbon dioxide $\left(X_{4}\right)$ of the CA, and harvest date $\left(X_{5}\right)$ were considered for pears from the two growing locations; the three harvest dates were coded as 1, 2 and 3 in terms of variable $X_{5}$. The effects of the processing factors upon the quality

Table 1

Quality parameters of 'Rocha' pears from two growing locations and picked at three harvest dates, by 1 and $7 \mathrm{~d}$ of ripening $\left(18-20{ }^{\circ} \mathrm{C}\right)^{\mathrm{a}}$

\begin{tabular}{|c|c|c|c|c|}
\hline \multirow[t]{2}{*}{ Quality parameter } & \multirow[t]{2}{*}{ Growing location } & \multirow[t]{2}{*}{ Harvest date } & \multicolumn{2}{|c|}{ Time of ripening (d) } \\
\hline & & & 1 & 7 \\
\hline \multirow[t]{6}{*}{ Firmness $(N)$} & 1 & 1 & $52.7 \pm 9.0 \mathrm{ab}^{\mathrm{b}}$ & $48.5 \pm 12.0 \mathrm{a}$ \\
\hline & & 2 & $54.8 \pm 6.3 \mathrm{a}$ & $44.0 \pm 8.1 \mathrm{a}$ \\
\hline & & 3 & $47.1 \pm 7.1 \mathrm{~b}$ & $45.2 \pm 10.1 \mathrm{a}$ \\
\hline & 2 & 1 & $69.8 \pm 10.1 \mathrm{a}$ & $64.4 \pm 8.9 \mathrm{a}$ \\
\hline & & 2 & $58.2 \pm 7.5 \mathrm{~b}$ & $64.0 \pm 5.9 \mathrm{a}$ \\
\hline & & 3 & $63.9 \pm 8.5 \mathrm{ab}$ & $59.7 \pm 6.1 \mathrm{a}$ \\
\hline \multirow[t]{6}{*}{ Hunter's $a^{*}$} & 1 & 1 & $-3.1 \pm 0.7 \mathrm{~b}$ & $-2.8 \pm 0.4 \mathrm{~b}$ \\
\hline & & 2 & $-2.5 \pm 0.7 \mathrm{ab}$ & $-2.8 \pm 0.4 \mathrm{~b}$ \\
\hline & & 3 & $-2.2 \pm 0.7 \mathrm{a}$ & $-2.3 \pm 0.3 \mathrm{a}$ \\
\hline & 2 & 1 & $-3.4 \pm 0.7 \mathrm{a}$ & $-3.3 \pm 0.9 \mathrm{a}$ \\
\hline & & 2 & $-3.2 \pm 1.0 \mathrm{a}$ & $-3.1 \pm 0.7 \mathrm{a}$ \\
\hline & & 3 & $-2.7 \pm 0.5 \mathrm{a}$ & $-2.8 \pm 0.4 \mathrm{a}$ \\
\hline \multirow[t]{6}{*}{ Hunter's $b^{*}$} & 1 & 1 & $13.2 \pm 1.8 \mathrm{a}$ & $13.3 \pm 2.0 \mathrm{a}$ \\
\hline & & 2 & $13.2 \pm 1.9 \mathrm{a}$ & $12.5 \pm 2.3 \mathrm{a}$ \\
\hline & & 3 & $11.2 \pm 2.0 \mathrm{a}$ & $10.4 \pm 0.7 \mathrm{~b}$ \\
\hline & 2 & 1 & $13.1 \pm 1.7 \mathrm{a}$ & $11.5 \pm 2.4 \mathrm{a}$ \\
\hline & & 2 & $10.9 \pm 0.8 \mathrm{~b}$ & $11.2 \pm 1.8 \mathrm{a}$ \\
\hline & & 3 & $10.6 \pm 1.9 \mathrm{~b}$ & $11.4 \pm 1.8 \mathrm{a}$ \\
\hline
\end{tabular}

${ }^{a}$ Data are means of 10 replicates \pm standard deviation.

${ }^{\mathrm{b}}$ Means separation within columns by Duncan's multiple range test $(P=0.05)$; significantly different means are followed by different letters $(a, b)$. 

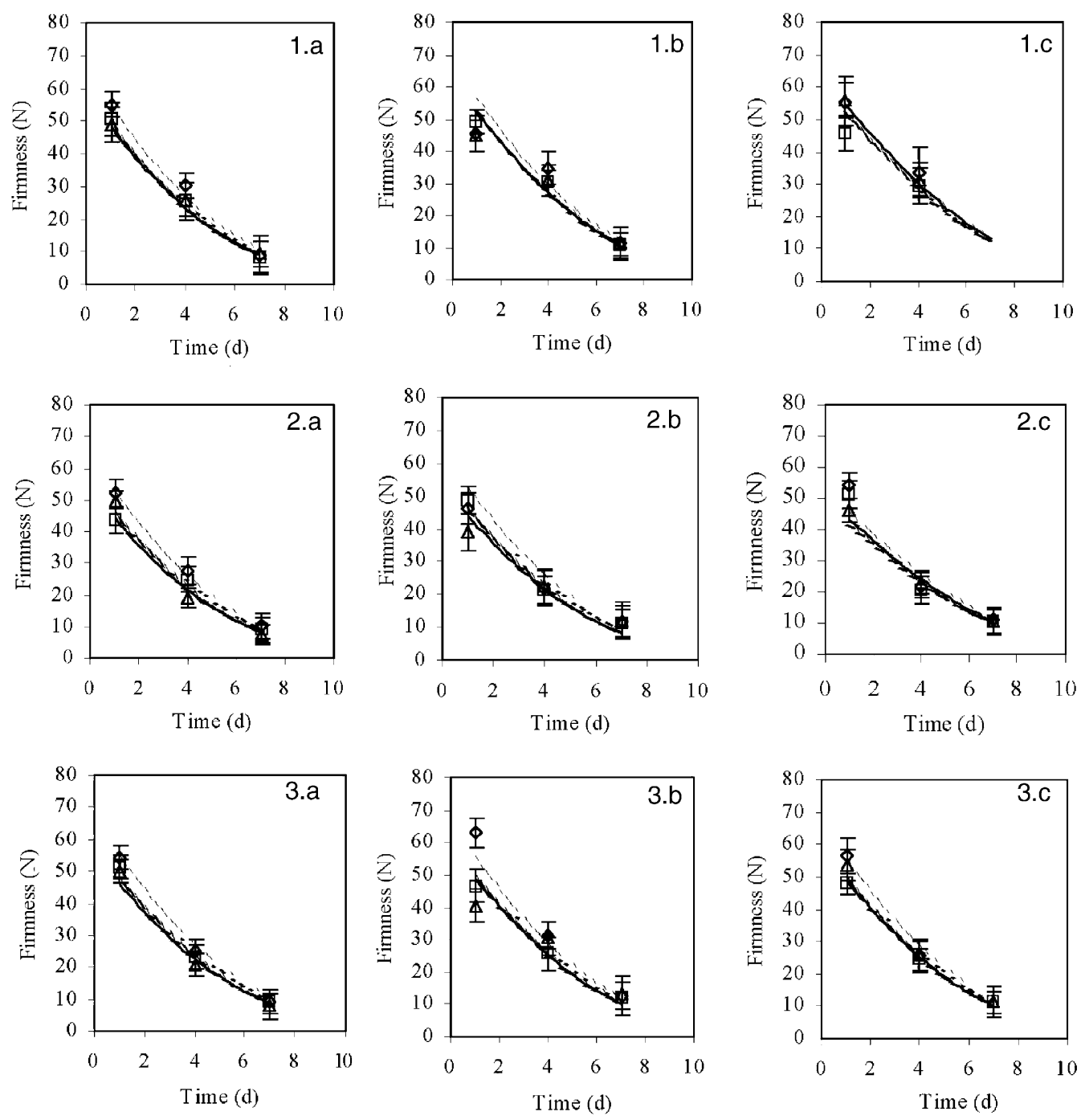

Fig. 1. Changes in firmness of 'Rocha' pears from Location 1, at different dates of harvest (pick 1: $\diamond ;$ pick 2: $\square$; pick 3: $\triangle$ ), throughout time in the open air at room temperature, after storage for 4 (a), 6 (b) and 9 (c) mo in air (1), under $2 \%(\mathrm{v} / \mathrm{v}) \mathrm{O}_{2}+0.5 \%(\mathrm{v} / \mathrm{v}) \mathrm{CO}_{2}(2)$ and under $2.5 \%(\mathrm{v} / \mathrm{v})$ $\mathrm{O}_{2}+0.7 \%(\mathrm{v} / \mathrm{v}) \mathrm{CO}_{2}$ (3). Each datum represents the average of at least 15 experimental values, and bars represent the associated standard deviation; the lines represent the fitted model (depicted as Eq. (1), with estimated parameters as listed in Table 2).

parameters were empirically modelled according to a second-order polynomial, using $X_{1}, X_{2}, X_{3}, X_{4}$ and $X_{5}$ as regressors, and firmness $\left(Y_{1}\right)$, Hunter's $a^{*}$ parameter $\left(Y_{2}\right)$ and $b^{*}$ parameter $\left(Y_{3}\right)$ as dependent variables, according to:

$$
\begin{aligned}
Y= & b_{0}+b_{1} X_{1}+b_{2} X_{2}+b_{3} X_{3}+b_{4} X_{4}+b_{5} X_{5} \\
& +b_{11} X_{1}^{2}+b_{12} X_{1} X_{2}+b_{13} X_{1} X_{3}+b_{14} X_{1} X_{4} \\
& +b_{15} X_{1} X_{5}+b_{22} X_{2}^{2}+b_{23} X_{2} X_{3}+b_{24} X_{2} X_{4} \\
& +b_{25} X_{2} X_{5}+b_{33} X_{3}^{2}+b_{34} X_{3} X_{4}+b_{35} X_{3} X_{5} \\
& +b_{44} X_{4}^{2}+b_{45} X_{4} X_{5}+b_{55} X_{5}^{2}
\end{aligned}
$$

where $b_{0}$ is the intercept; $b_{1}, b_{2}, b_{3}, b_{4}$ and $b_{5}$ are linear parameters; $b_{11}, b_{22}, b_{33}, b_{44}$ and $b_{55}$ are quadratic parameters; and $b_{12}, b_{13}, b_{14}, b_{15}, b_{23}, b_{24}, b_{25}, b_{34}, b_{35}$ and $b_{45}$ are two-way interaction parameters. The experi- mental data were fitted to by Eq. (1) via multiple linear regression using the software SPSS (v. 9.0, from SPSS, USA), with $F \geqslant 0.005$ set as criterion of significance for the adjustable parameters. Experimental data arising from replicates that were more than two standard deviations apart from their average were rejected as outliers.

\section{Results and discussion}

\section{Influence of growing location, date of harvest and atmosphere gas composition on firmness changes}

\section{At harvest}

The values of firmness of pears from locations 1 and 2 at the three harvest dates are presented in Table 1 . 
Table 2

Second-order polynomial model including only the statistically significant parameters $(P<0.05)$, and best fit estimates of parameters \pm confidence intervals (CI) coupled with actual value for the adjusted coefficient of determination $\left(R_{\text {adj }}^{2}\right)$, pertaining to firmness of 'Rocha' pears from two different growing locations

\begin{tabular}{|c|c|c|c|c|c|}
\hline Location & Model & Parameter & $\begin{array}{l}\text { Estimated value } \pm \text { CI } \\
(95 \%)\end{array}$ & Unit & $R_{\mathrm{adj}}^{2}$ \\
\hline 1 & $\begin{aligned} \ln Y_{1}= & b_{0}+b_{2} X_{2}+b_{3} X_{3}+b_{5} X_{5}+b_{11} X_{12} \\
& +b_{12} X_{1} X_{2}+b_{13} X_{1} X_{3}+b_{14} X_{1} X_{4} \\
& +b_{15} X_{1} X_{5}+b_{22} X_{2}^{2}+b_{55} X_{5}^{2}\end{aligned}$ & $\begin{array}{l}b_{0} \\
b_{2} \\
b_{3} \\
b_{5} \\
b_{11} \\
b_{12} \\
b_{13} \\
b_{14} \\
b_{15} \\
b_{22} \\
b_{55}\end{array}$ & $\begin{array}{c}1.88 \pm 0.04 \\
-0.092 \pm 0.010 \\
-0.002 \pm 0.002 \\
-0.13 \pm 0.04 \\
-0.003 \pm 0.000 \\
-0.004 \pm 0.001 \\
0.001 \pm 0.000 \\
0.023 \pm 0.003 \\
0.005 \pm 0.002 \\
-0.005 \pm 0.001 \\
0.019 \pm 0.008\end{array}$ & $\begin{array}{l}\text { Dimensionless } \\
\mathrm{d}^{-1} \\
(\% \mathrm{v} / \mathrm{v})^{-1} \\
\text { Dimensionless } \\
\mathrm{mo}^{-2} \\
\mathrm{mo}^{-1} \times \mathrm{d}^{-1} \\
\mathrm{mo}^{-1} \times(\% \mathrm{v} / \mathrm{v})^{-1} \\
\mathrm{mo}^{-1} \times(\% \mathrm{v} / \mathrm{v})^{-1} \\
\mathrm{mo}^{-1} \\
\mathrm{~d}^{-2} \\
\text { Dimensionless }\end{array}$ & 0.92 \\
\hline 2 & $\begin{aligned} \ln Y_{1}= & b_{0}+b_{1} X_{1}+b_{2} X_{2}+b_{3} X_{3}+b_{11} X_{1}^{2} \\
& +b_{12} X_{1} X_{2}+b_{13} X_{1} X_{3}+b_{23} X_{2} X_{3} \\
& +b_{25} X_{2} X_{5}+b_{35} X_{3} X_{5}\end{aligned}$ & $\begin{array}{l}b_{0} \\
b_{1} \\
b_{2} \\
b_{3} \\
b_{11} \\
b_{12} \\
b_{13} \\
b_{23} \\
b_{25} \\
b_{35}\end{array}$ & $\begin{array}{c}1.78 \pm 0.08 \\
0.11 \pm 0.02 \\
-0.196 \pm 0.007 \\
0.009 \pm 0.002 \\
-0.011 \pm 0.003 \\
0.014 \pm 0.000 \\
-0.0015 \pm 0.0004 \\
0.0020 \pm 0.0007 \\
-0.006 \pm 0.002 \\
-0.0008 \pm 0.0002\end{array}$ & $\begin{array}{l}\text { Dimensionless } \\
\mathrm{mo}^{-1} \\
\mathrm{~d}^{-1} \\
(\% \mathrm{v} / \mathrm{v})^{-1} \\
\mathrm{mo}^{-2} \\
\mathrm{mo}^{-1} \times \mathrm{d}^{-1} \\
\mathrm{mo}^{-1} \times(\% \mathrm{v} / \mathrm{v})^{-1} \\
\mathrm{~d}^{-1} \times(\% \mathrm{v} / \mathrm{v})^{-1} \\
\mathrm{~d}^{-1} \\
(\% \mathrm{v} / \mathrm{v})^{-1}\end{array}$ & 0.89 \\
\hline
\end{tabular}

Analyses of these experimental data revealed that firmness was different $(P \leqslant 0.05)$ between pears grown in the two locations. Firmness of pears from the two locations was also influenced by the date of harvest and the ripening time. By $1 \mathrm{~d}$ of exposure to the open air, pears from location 1 and from the second harvest date were firmer than those from the third date (see Table 1). The firmness of pears decreased after $7 \mathrm{~d}$ of exposure to the open air at room temperature; however, no significant differences $(P \leqslant 0.05)$ were found between the firmness of pears picked up at the various dates (see Table 1).

For pears grown in location 2 and by $1 \mathrm{~d}$ of exposure to the open air at room temperature, significant differences were found between fruits picked at sequential dates (see Table 1). By $7 \mathrm{~d}$ of exposure to the open air at room temperature, no statistically significant differences could be found between firmness values. As reported by Kvåle (1977), firmness of pears was lower at late harvest dates, but those differences tended to vanish as ripening time elapsed.

\section{After storage}

Pears from the first harvest date grown in location 1 were significantly firmer than those from the second and third. The effect of the date of harvest persisted throughout storage in pears stored under all conditions; however, this effect became less apparent as time in the open air elapsed (see Fig. 1). When pears were exposed to the open air at room temperature, firmness decreased in pears stored under all conditions, as confirmed by the negative value of parameters $b_{2}$ and $b_{22}$ (see Table 2). Firmness also tended to decrease throughout storage in pears under all conditions, as confirmed by the negative value of parameter $b_{11}$ (Table 2); the interaction of storage time with time of exposure to the open air exhibited a negative influence upon firmness, as confirmed by the negative value of $b_{12}$.

For pears grown in location 2 the differences after storage and throughout ripening, between pears picked at different dates of harvest were larger for fruits stored under air than for those stored under CA conditions (see Fig. 2). Furthermore, the effect conveyed by the date of harvest confirms that fruits picked later exhibited a tendency for a lower firmness after they were removed from storage. From 4 to 6 mo of storage, the changes in firmness of pears under all conditions were essentially negligible, whereas from 6 to 9 mo one detected a decrease in firmness of pears from all conditions. When pears were exposed to the open air at room temperature, their firmness decreased irrespective of the processing conditions (as apparent from the negative value for parameter $b_{2}$ ), especially until $4 \mathrm{~d}$ of exposure to the open air (see Table 2). The concentration of $\mathrm{O}_{2}$ played, 

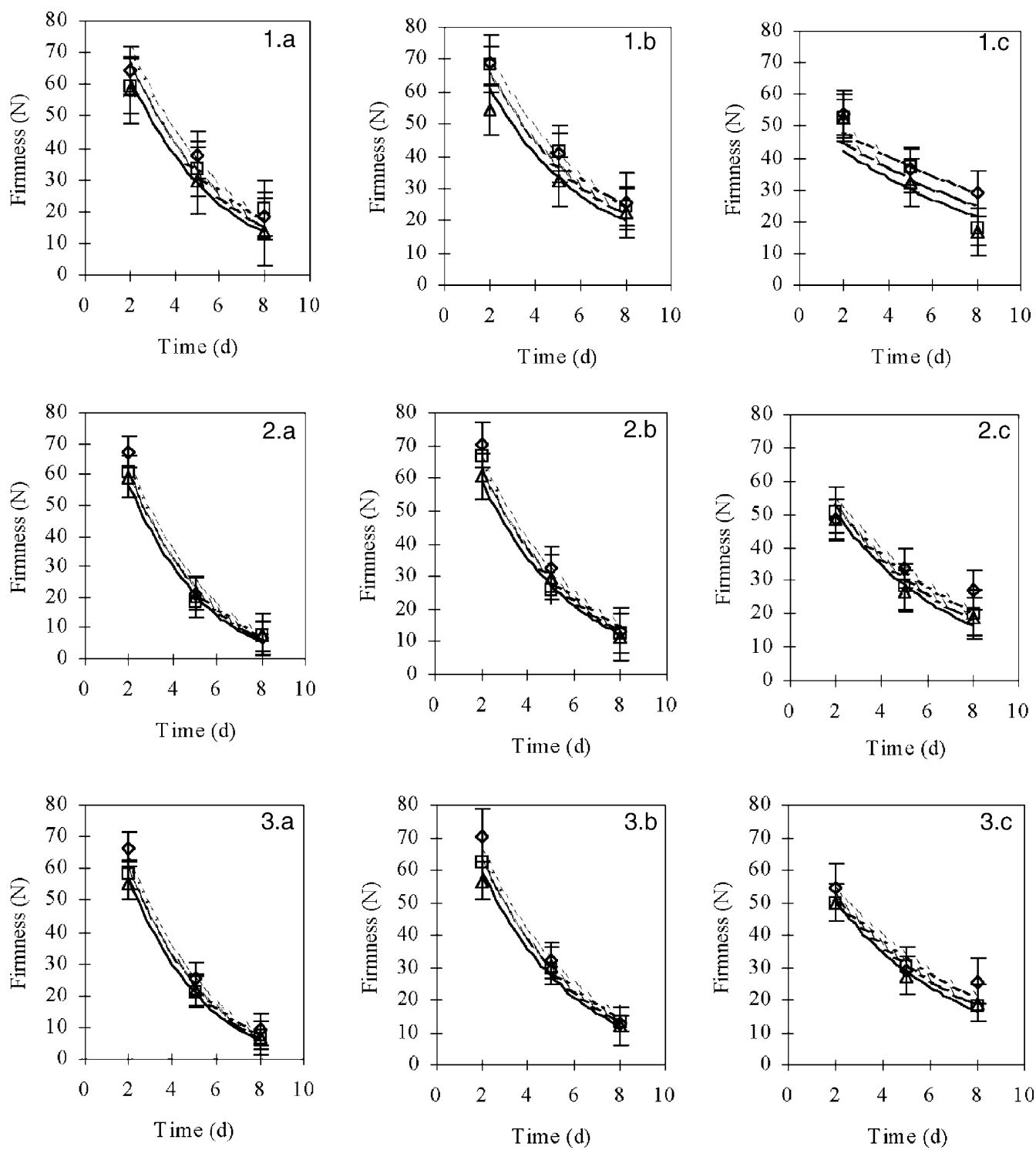

Fig. 2. Changes in firmness of 'Rocha' pears from Location 2, at different dates of harvest (pick 1: $\diamond$; pick 2: $\square$; pick 3: $\triangle$ ), throughout time in the open air at room temperature, after storage for 4 (a), 6 (b) and 9 (c) mo in air (1), under $2 \%(\mathrm{v} / \mathrm{v}) \mathrm{O}_{2}+0.5 \%(\mathrm{v} / \mathrm{v}) \mathrm{CO}_{2}(2)$ and under $2.5 \%(\mathrm{v} / \mathrm{v})$ $\mathrm{O}_{2}+0.7 \%(\mathrm{v} / \mathrm{v}) \mathrm{CO}_{2}(3)$. Each datum represents the average of at least 15 experimental values, and bars represent the associated standard deviation; the lines represent the fitted model (depicted as Eq. (1), with estimated parameters as listed in Table 2).

nevertheless, a positive role on firmness changes (see positive value of parameter $b_{3}$ ); this effect was clearly confirmed for pears stored in air, which exhibited a higher firmness than those stored under CA conditions.

Our results encompassing firmness response to the various storage conditions were strongly dependent on the growing location, as reported elsewhere for apples (Sharples \& Johnson, 1987). Decreases in firmness of pears throughout storage was also observed for Doyene du Comice pears picked at several dates of harvest, and stored for 3, 5 and 7 mo under $2 \%(\mathrm{v} / \mathrm{v}) \mathrm{O}_{2}$ coupled with $0.7 \%$ and $5 \%(\mathrm{v} / \mathrm{v}) \mathrm{CO}_{2}$, as well as in air (López, Miró, \& Graell, 2001).
Influence of growing location, date of harvest and atmosphere gas composition Hunter's $a^{*}$ parameter

\section{At harvest}

Hunter's $a^{*}$ value pertaining to pears from locations 1 and 2 at harvest time are presented in Table 1. Analysis of the colour data revealed differences between pears from those locations. For pears grown in location 1 and by $1 \mathrm{~d}$ of exposure to the open air, fruits from the first harvest date exhibited a lower $a^{*}$ value than those from the third. By $7 \mathrm{~d}$ in the open air at room temperature, pears from the first and second harvest dates presented lower $a^{*}$ values than those from the third. 

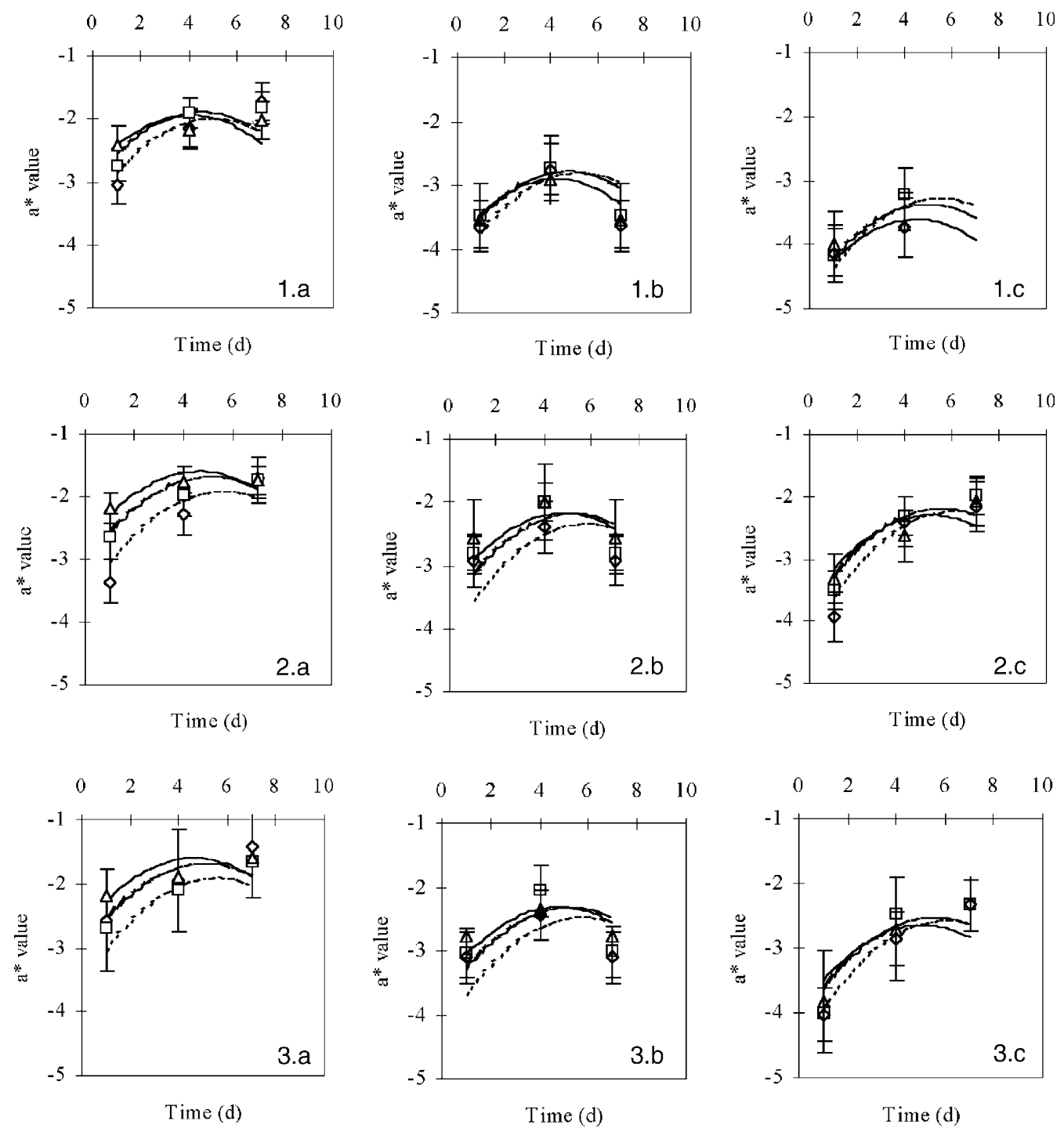

Fig. 3. Changes in Hunter's $a^{*}$ value of 'Rocha' pears from Location 1, at different dates of harvest (pick 1: $\diamond$; pick 2: $\square$; pick 3: $\triangle$ ), throughout time in the open air at room temperature, after storage for 4 (a), 6 (b) and 9 (c) mo in air (1), under $2 \%(\mathrm{v} / \mathrm{v}) \mathrm{O}_{2}+0.5 \%(\mathrm{v} / \mathrm{v}) \mathrm{CO}_{2}(2)$ and under $2.5 \%(\mathrm{v} / \mathrm{v})$ $\mathrm{O}_{2}+0.7 \%(\mathrm{v} / \mathrm{v}) \mathrm{CO}_{2}$ (3). Each datum represents the average of at least 15 experimental values, and bars represent the associated standard deviation; the lines represent the fitted model (depicted as Eq. (1), with estimated parameters as listed in Table 3).

For pears grown in location 2, no significant differences were found between the dates of harvest in terms of $a^{*}$ values (see Table 1).

\section{After storage}

For pears grown in location 1, Hunter's $a^{*}$ value decreased throughout storage time for pears under all conditions (see Fig. 3); said decrease was confirmed by the negative value of parameter $b_{1}$ (see Table 3 ). When fruits were exposed to the open air at room temperature, the $a^{*}$ value increased for pears under all conditions (see Fig. 3) except for 6 mo of CA storage, for which this parameter decreased between 4 and $7 \mathrm{~d}$ of exposure to the open air. The influence of the date of harvest was clear by 4 mo of storage and $1 \mathrm{~d}$ of exposure to the open air (see Fig. 3). The lowest $a^{*}$ value was observed for pears from the first date of harvest, and the highest for pears from the third; these differences tended to decrease during the time of exposure to the open air. Differences in the $a^{*}$ values between storage conditions were apparent by 6 and 9 mo of storage (see Fig. 3). Pears stored under air exhibited lower $a^{*}$ values than those stored under CA conditions.

For pears that had been grown in location 2, as storage time elapsed Hunter's $a^{*}$ values tended to decrease for fruits taken at every date of harvest (as ap- 
Table 3

Second-order polynomial model including only the statistically significant parameters $(P<0.05)$, and best fit estimates of parameters \pm confidence intervals (CI) coupled with actual value for the adjusted coefficient of determination $\left(R_{\text {adj }}^{2}\right)$, pertaining to Hunter's $a^{*}$ parameter of 'Rocha' pears from two different growing locations

\begin{tabular}{|c|c|c|c|c|c|}
\hline Location & Model & Parameter & $\begin{array}{l}\text { Estimated } \\
\text { value } \pm \text { CI }(95 \%)\end{array}$ & Unit & $R_{\mathrm{adj}}^{2}$ \\
\hline 1 & $\begin{aligned} Y_{2}= & b_{0}+b_{1} X_{1}+b_{2} X_{2}+b_{3} X_{3}+b_{5} X_{5}+b_{11} X_{1}^{2} \\
& +b_{12} X_{1} X_{2}+b_{13} X_{1} X_{3}+b_{14} X_{1} X_{4}+b_{15} X_{1} X_{5} \\
& +b_{22} X_{2}^{2}+b_{23} X_{2} X_{3}+b_{25} X_{2} X_{5}+b_{35} X_{3} X_{5} \\
& +b_{44} X_{4}^{2}+b_{55} X_{5}^{2}\end{aligned}$ & $\begin{array}{l}b_{0} \\
b_{1} \\
b_{2} \\
b_{3} \\
b_{5} \\
b_{11} \\
b_{12} \\
b_{13} \\
b_{14} \\
b_{15} \\
b_{22} \\
b_{23} \\
b_{25} \\
b_{35} \\
b_{44} \\
b_{55}\end{array}$ & $\begin{array}{l}-2.6 \pm 0.8 \\
-0.5 \pm 0.2 \\
0.6 \pm 0.1 \\
-0.07 \pm 0.02 \\
0.9 \pm 0.3 \\
0.05 \pm 0.02 \\
-0.009 \pm 0.002 \\
-0.020 \pm 0.004 \\
-0.3 \pm 0.2 \\
-0.03 \pm 0.02 \\
-0.05 \pm 0.01 \\
-0.003 \pm 0.002 \\
-0.05 \pm 0.02 \\
-0.008 \pm 0.005 \\
1.0 \pm 0.9 \\
-0.09 \pm 0.07\end{array}$ & $\begin{array}{l}\text { Dimensionless } \\
\mathrm{mo}^{-1} \\
\mathrm{~d}^{-1} \\
(\% \mathrm{v} / \mathrm{v})^{-1} \\
\text { Dimensionless } \\
\mathrm{mo}^{-2} \\
\mathrm{mo}^{-1} \times \mathrm{d}^{-1} \\
\mathrm{mo}^{-1} \times(\% \mathrm{v} / \mathrm{v})^{-1} \\
\mathrm{mo}^{-1} \times(\% \mathrm{v} / \mathrm{v})^{-1} \\
\mathrm{mo}^{-1} \\
\mathrm{~d}^{-2} \\
\mathrm{~d}^{-1} \times(\% \mathrm{v} / \mathrm{v})^{-1} \\
\mathrm{~d}^{-1} \\
(\% \mathrm{v} / \mathrm{v})^{-1} \\
(\% \mathrm{v} / \mathrm{v})^{-2} \\
\text { Dimensionless }\end{array}$ & 0.67 \\
\hline 2 & $\begin{aligned} Y_{2}= & b_{0}+b_{1} X_{1}+b_{2} X_{2}+b_{3} X_{3} \\
& +b_{5} X_{5}+b_{11} X_{1}^{2}+b_{12} X_{1} X_{2}+b_{13} X_{1} X_{3} \\
& +b_{14} X_{1} X_{4}+b_{22} X_{2}^{2}+b_{23} X_{2} X_{3}+b_{25} X_{2} X_{5} \\
& +b_{35} X_{3} X_{5}+b_{44} X_{4}^{2}\end{aligned}$ & $\begin{array}{l}b_{0} \\
b_{1} \\
b_{2} \\
b_{3} \\
b_{5} \\
b_{11} \\
b_{12} \\
b_{13} \\
b_{14} \\
b_{22} \\
b_{23} \\
b_{25} \\
b_{35} \\
b_{44}\end{array}$ & $\begin{array}{c}-2.6 \pm 0.6 \\
-0.3 \pm 0.2 \\
0.20 \pm 0.09 \\
-0.06 \pm 0.02 \\
0.20 \pm 0.08 \\
0.04 \pm 0.01 \\
-0.007 \pm 0.006 \\
-0.020 \pm 0.005 \\
-0.3 \pm 0.1 \\
0.007 \pm 0.006 \\
-0.005 \pm 0.002 \\
-0.020 \pm 0.004 \\
0.006 \pm 0.003 \\
1.6 \pm 0.9\end{array}$ & $\begin{array}{l}\text { Dimensionless } \\
\mathrm{mo}^{-1} \\
\mathrm{~d}^{-1} \\
(\% \mathrm{v} / \mathrm{v})^{-1} \\
\text { Dimensionless } \\
\mathrm{mo}^{-2} \\
\mathrm{mo}^{-1} \times \mathrm{d}^{-1} \\
\mathrm{mo}^{-1} \times(\% \mathrm{v} / \mathrm{v})^{-1} \\
\mathrm{mo}^{-1} \times(\% \mathrm{v} / \mathrm{v})^{-1} \\
\mathrm{~d}^{-2} \\
\mathrm{~d}^{-1} \times(\% \mathrm{v} / \mathrm{v})^{-1} \\
\mathrm{~d}^{-1} \\
(\% \mathrm{v} / \mathrm{v})^{-1} \\
(\% \mathrm{v} / \mathrm{v})^{-2}\end{array}$ & 0.66 \\
\hline
\end{tabular}

parent by the negative value of $b_{1}$ ); that decrease was influenced by the interaction between the storage time and the concentrations of $\mathrm{O}_{2}$ and $\mathrm{CO}_{2}$ in the gas (see Table 3). The decrease of Hunter's $a^{*}$ value throughout storage for pears stored in air was more evident than for pears stored under CA conditions. After removal from storage, the $a^{*}$ values increased for pears from the CA conditions, but tended to remain constant for pears stored in air (see Fig. 4 and Table 3). The influence of the date of harvest was clear in pears from all storage conditions; pears from the first date of harvest presented the lowest $a^{*}$ values, and pears from the third the highest ones (see positive value of parameter $b_{5}$ ). Even stronger differences between the dates of harvest were detected in pears stored in air than in those stored under CA conditions (see Fig. 4); however, such differences became less apparent as time of exposure to the open air elapsed. No clear differences in terms of $a^{*}$ values of pears were observed between the two CA conditions.
Infuence of growing location, date of harvest and atmospheregas composition on Hunter's b* parameter

\section{At harvest}

Hunter's $b^{*}$ values of pears grown in location 1 and 2 are shown in Table 1. For pears grown in location 1 and by $1 \mathrm{~d}$ of exposure to the open air at room temperature, no differences were observed in terms of $b^{*}$ for the various dates of harvest (see Table 1). By $7 \mathrm{~d}$ of exposure to the open air at room temperature, pears from the first and second harvest dates presented higher $b^{*}$ values than those from the third harvest one.

For pears grown in location 2 , the $b^{*}$ values by $1 \mathrm{~d}$ of exposure to the open air at room temperature were higher for fruits from the first harvest date than for those from the second and third. By $7 \mathrm{~d}$ of exposure to the open air, pears from all dates of harvest exhibited essentially the same level in terms of $b^{*}$ value (see Table $1)$. 

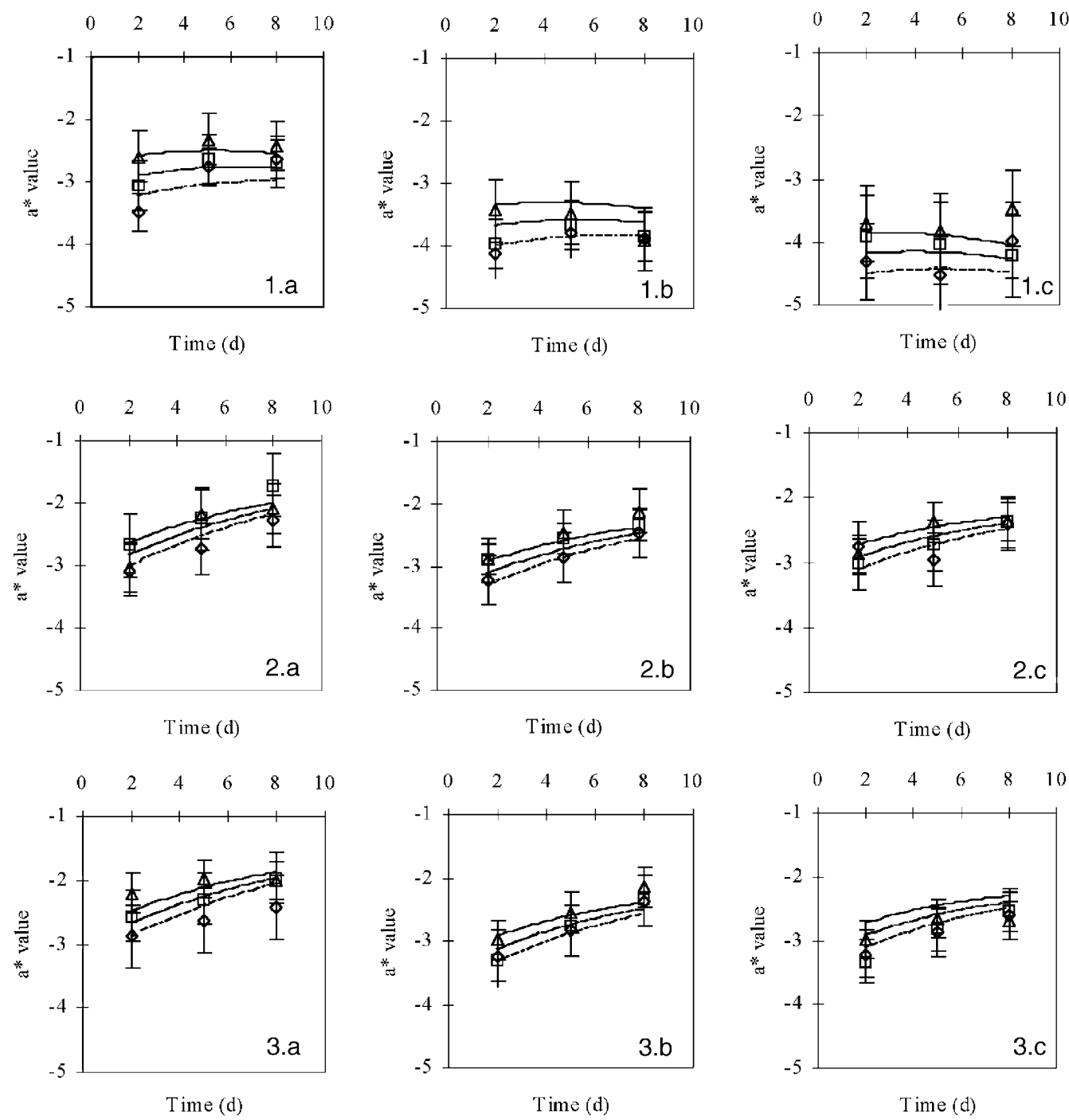

Fig. 4. Changes in Hunter's $a^{*}$ value of 'Rocha' pears from Location 2, at different dates of harvest (pick 1: $\diamond$; pick 2: $\square$; pick 3: $\triangle$ ), throughout time in the open air at room temperature, after storage for 4 (a), 6 (b) and 9 (c) mo in air (1), under $2 \%(\mathrm{v} / \mathrm{v}) \mathrm{O}_{2}+0.5 \%(\mathrm{v} / \mathrm{v}) \mathrm{CO}_{2}(2)$ and under $2.5 \%(\mathrm{v} / \mathrm{v})$ $\mathrm{O}_{2}+0.7 \%(\mathrm{v} / \mathrm{v}) \mathrm{CO}_{2}$ (3). Each datum represents the average of at least 15 experimental values, and bars represent the associated standard deviation; the lines represent the fitted model (depicted as Eq. (1), with estimated parameters as listed in Table 3).

\section{After storage}

Throughout storage, the $b^{*}$ values of pears grown in location 1 increased for fruits under all conditions (as concluded from the positive value of parameter $b_{1}$ ); that increase was especially notorious between 4 and 6 mo of storage (see Fig. 5). When pears were exposed to the open air at room temperature, the $b^{*}$ values decreased under all conditions, but exhibited a tendency to increase after $6 \mathrm{~d}$ of exposure to the open air. These results were confirmed by the regression analysis, via a negative value for $b_{2}$ and a positive value for $b_{22}$ (see Table 4). Pears stored under air showed higher $b^{*}$ values than those stored under CA conditions, and this tendency became clearer as storage time elapsed. By 4 mo of storage, the differences between the dates of harvest were visible in pears stored under all conditions (see Fig. 5). Pears from the first harvest date presented the highest $b^{*}$ values, and those from the third the lowest. The effect of the date of harvest decreased over time of exposure to the open air at room temperature, and by $7 \mathrm{~d}$ differences were hardly detected. By 6 mo of storage, only the pears taken at the first date of harvest were distinct from pears from the other harvest dates; by 9 mo of storage, no differences were observed in terms of $b^{*}$ values among pears from the various dates of harvest (see Fig. 5). 

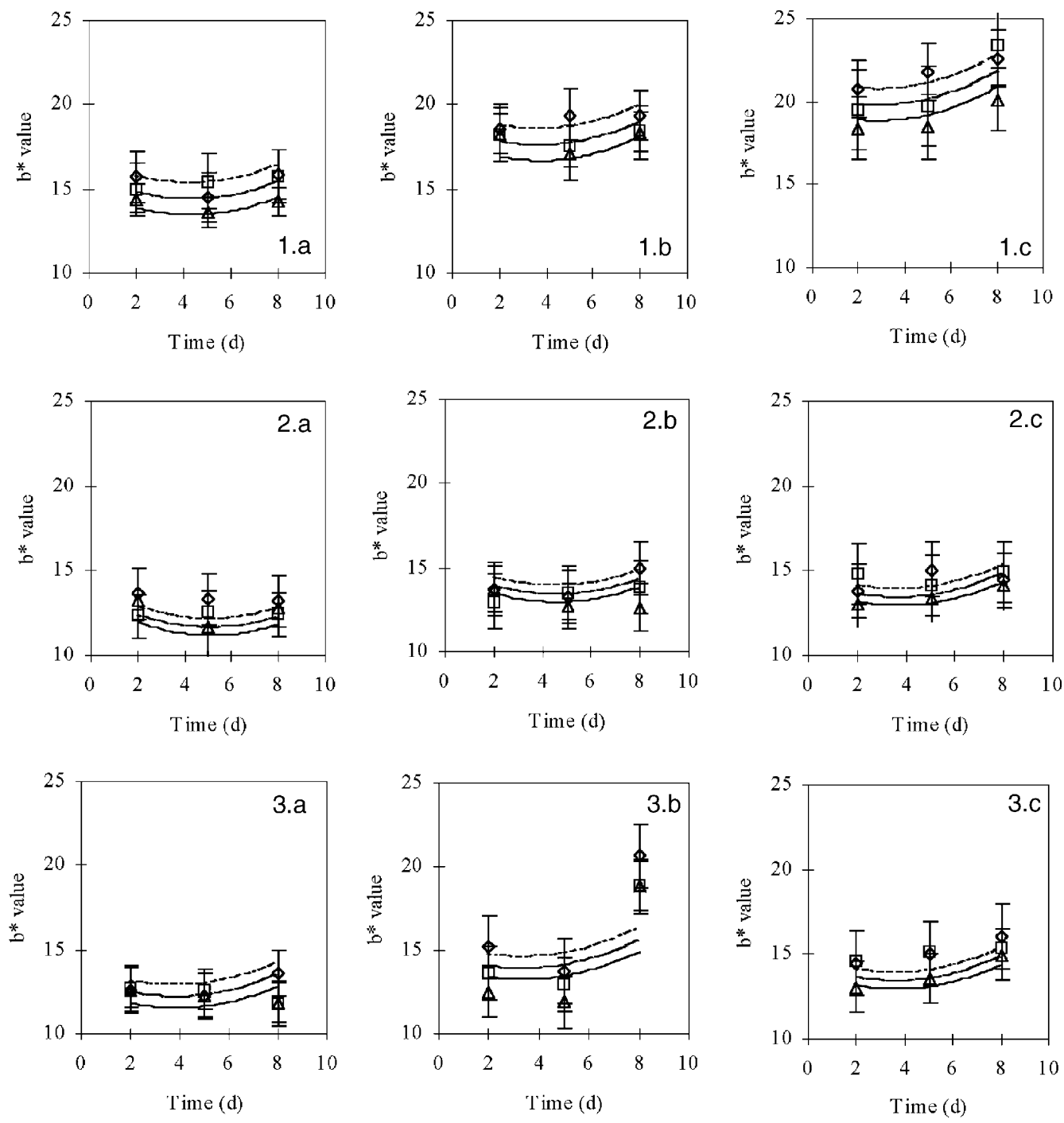

Fig. 5. Changes in Hunter's $b^{*}$ value of 'Rocha' pears from Location 1, at different dates of harvest (pick 1: $\diamond$; pick 2: $\square$; pick 3: $\triangle$ ), throughout time in the open air at room temperature, after storage for 4 (a), 6 (b) and 9 (c) mo in air (1), under $2 \%(\mathrm{v} / \mathrm{v}) \mathrm{O}_{2}+0.5 \%(\mathrm{v} / \mathrm{v}) \mathrm{CO}_{2}(2)$ and under $2.5 \%(\mathrm{v} / \mathrm{v})$ $\mathrm{O}_{2}+0.7 \%(\mathrm{v} / \mathrm{v}) \mathrm{CO}_{2}$ (3). Each datum represents the average of at least 15 experimental values, and bars represent the associated standard deviation; the lines represent the fitted model (depicted as Eq. (1), with estimated parameters as listed in Table 4).

For pears grown in location 2, the $b^{*}$ values tended to increase over storage time (as apparent in the positive value of parameter $b_{1}$ ), especially for pears stored in air (see Fig. 6). When pears were exposed to the open air at room temperature, the $b^{*}$ values tended to increase, especially between 5 and $8 \mathrm{~d}$. Pears stored in air presented higher $b^{*}$ values than those stored under the CA conditions. The influence of the date of harvest was also dependent on the storage conditions; pears from the first harvest date showed higher $b^{*}$ values than those from the second, and these had in turn higher $b^{*}$ values than those from the third harvest date - this influence was more apparent in pears stored under air.
By the harvest time, pears picked earlier were less mature, and exhibited lower $a^{*}$ values than those obtained later. The rate of ripening (assessed by $b^{*}$ value evolution) throughout storage was decreased when CA conditions were employed. Irrespective of date of harvest or storage condition applied, colour decay took place, either via increase of Hunter's $a^{*}$ or decrease of $b^{*}$ values.

\section{Conclusions}

Pears from location 2 were firmer than those from location 1. However, firmness response of pears 
Table 4

Second-order polynomial model including only the statistically significant parameters $(P<0.05)$, and best fit estimates of parameters \pm confidence intervals $(\mathrm{CI})$ coupled with actual value for the adjusted coefficient of determination $\left(R_{\text {adj }}^{2}\right)$, pertaining to Hunter's $b^{*}$ parameter of 'Rocha' pears from two different growing locations

\begin{tabular}{|c|c|c|c|c|c|}
\hline Location & Model & Parameter & $\begin{array}{l}\text { Estimated } \\
\text { value } \pm \text { CI }(95 \%)\end{array}$ & Unit & $R_{\mathrm{adj}}^{2}$ \\
\hline 1 & $\begin{aligned} Y_{3}= & b_{0}+b_{1} X_{1}+b_{2} X_{2}+b_{11} X_{1}^{2} \\
& +b_{12} X_{1} X_{2}+b_{13} X_{1} X_{3}+b_{15} X_{1} X_{5} \\
& +b_{22} X_{2}^{2} b_{25} X_{2} X_{5}+b_{3} X_{3} \\
& +b_{5} X_{5}+b_{55} X_{5}^{2}\end{aligned}$ & $\begin{array}{l}b_{0} \\
b_{1} \\
b_{2} \\
b_{11} \\
b_{12} \\
b_{13} \\
b_{15} \\
b_{22} \\
b_{23} \\
b_{24} \\
b_{35} \\
b_{45}\end{array}$ & $\begin{array}{c}8.1 \pm 3.0 \\
3.7 \pm 0.7 \\
-1.3 \pm 0.4 \\
-0.25 \pm 0.05 \\
0.05 \pm 0.03 \\
0.03 \pm 0.01 \\
0.12 \pm 0.09 \\
0.16 \pm 0.03 \\
0.13 \pm 0.08 \\
-0.06 \pm 0.05 \\
-2.9 \pm 1.5 \\
0.3 \pm 0.2\end{array}$ & $\begin{array}{l}\text { Dimensionless } \\
\mathrm{mo}^{-1} \\
\mathrm{~d}^{-1} \\
\mathrm{mo}^{-2} \\
\mathrm{mo}^{-1} \times \mathrm{d}^{-1} \\
\mathrm{mo}^{-1} \times(\% \mathrm{v} / \mathrm{v})^{-1} \\
\mathrm{mo}^{-1} \\
\mathrm{~d}^{-2} \\
\mathrm{~d}^{-1} \times(\% \mathrm{v} / \mathrm{v})^{-1} \\
\mathrm{~d}^{-1} \times(\% \mathrm{v} / \mathrm{v})^{-1} \\
(\% \mathrm{v} / \mathrm{v})^{-1} \\
(\% \mathrm{v} / \mathrm{v})^{-1}\end{array}$ & 0.49 \\
\hline 2 & $\begin{aligned} Y_{3}= & b_{0}+b_{1} X_{1}+b_{2} X_{2}+b_{11} X_{1}^{2}+b_{12} X_{1} X_{2} \\
& +b_{13} X_{1} X_{3}+b_{22} X_{2}^{2} b_{23} X_{2} X_{3} \\
& +b_{24} X_{2} X_{4}+b_{35} X_{3} X_{5}+b_{45} X_{4} X_{5}\end{aligned}$ & $\begin{array}{l}b_{0} \\
b_{1} \\
b_{2} \\
b_{11} \\
b_{12} \\
b_{13} \\
b_{22} \\
b_{23} \\
b_{24} \\
b_{35} \\
b_{45}\end{array}$ & $\begin{array}{l}8.0 \pm 2.1 \\
2.3 \pm 0.6 \\
-1.5 \pm 0.4 \\
-0.20 \pm 0.05 \\
0.04 \pm 0.02 \\
0.040 \pm 0.005 \\
0.07 \pm 0.02 \\
0.03 \pm 0.01 \\
0.8 \pm 0.3 \\
-0.04 \pm 0.2 \\
-0.8 \pm 0.3\end{array}$ & $\begin{array}{l}\text { Dimensionless } \\
\mathrm{mo}^{-1} \\
\mathrm{~d}^{-1} \\
\mathrm{mo}^{-2} \\
\mathrm{mo}^{-1} \times \mathrm{d}^{-1} \\
\mathrm{mo}^{-1} \times(\% \mathrm{v} / \mathrm{v})^{-1} \\
\mathrm{~d}^{-2} \\
\mathrm{~d}^{-1} \times(\% \mathrm{v} / \mathrm{v})^{-1} \\
\mathrm{~d}^{-1} \times(\% \mathrm{v} / \mathrm{v})^{-1} \\
(\% \mathrm{v} / \mathrm{v})^{-1} \\
(\% \mathrm{v} / \mathrm{v})^{-1}\end{array}$ & 0.66 \\
\hline
\end{tabular}

obtained at different dates of harvest seemed to follow essentially the same pattern, no matter their growing location; pears from the first date of harvest were firmer than those from the second, and these in turn firmer than those from the third. Firmness response to storage conditions and dates of harvest was also dependent on the growing location. In the case of pears grown in location 1, the differences between dates of harvest were clearer in fruits stored under CA conditions; for pears from location 2, harvest differences were clearer in pears stored in air. For pears from both locations, the effect of the date of harvest decreased during the time of ripening. Firmness tended to decrease throughout storage time, as expected.

The response of $a^{*}$ values to the various dates of harvest depended also on the growing location. For pears grown in location 1 , the differences between dates of harvest were clearly observed in fruits stored under CA conditions, unlike pears from location 2 for which differences were more apparent between fruits stored in air. In general, pears from the first date of harvest presented the lowest $a^{*}$ values; and the $a^{*}$ values tended to decrease throughout storage time, especially in the case of pears stored in air.

The effect of the date of harvest on the $b^{*}$ values depended also on the growing location. For pears grown in location 1 , the effect of the date of harvest did not persist throughout storage time and time of ripening. For pears from location 2, larger differences between dates of harvest were observed in the case of fruits stored in air.

In general, the influence of the date of harvest on 'Rocha' pears was found to be less important when fruits were long-term stored under CA conditions, e.g. $2 \%(\mathrm{v} / \mathrm{v})$ or $2.5 \%(\mathrm{v} / \mathrm{v}) \mathrm{O}_{2}$, in combination with $0.5 \%(\mathrm{v} / \mathrm{v})$ or $0.7 \%(\mathrm{v} / \mathrm{v}) \mathrm{CO}_{2}$. The growing location is apparently a determinant factor for the final quality and shelf-life of pear under CA storage.

\section{Acknowledgements}

This research was partially funded by project PAMAF 6034 (Study of the effects of the pedo-climatic conditions, of the nutritional stage of the orchard and of the postharvest operations on the quality and preservation ability of pear cv. Rocha, in different controlled atmosphere conditions) coordinated by INIA (Portugal). The first and second authors acknowledge financial support from FCT (Portugal), via fellowships BD/ 18392/98 and SFRH/BPD/1601/2000, respectively. 

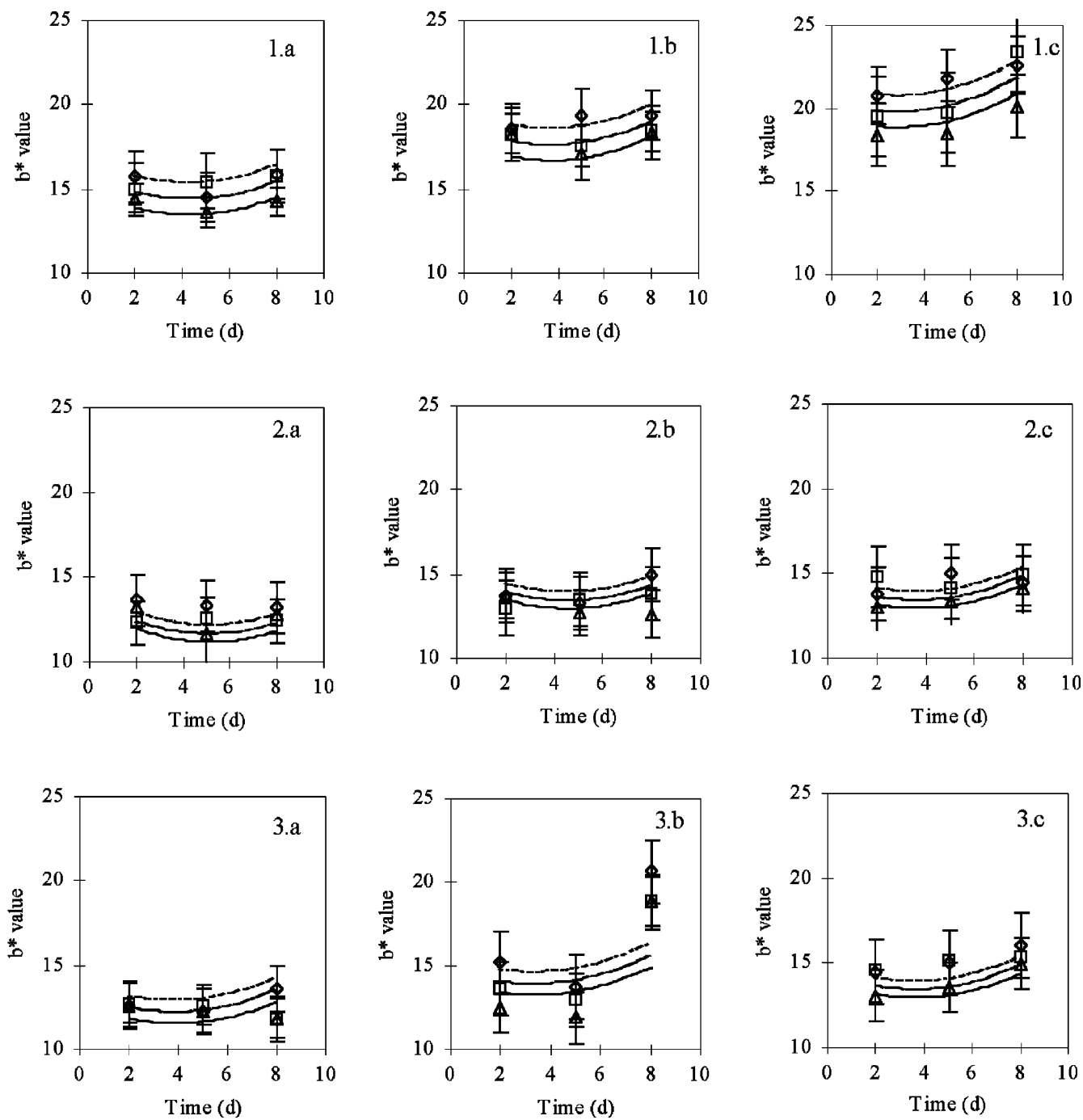

Fig. 6. Changes in Hunter's $b^{*}$ value of 'Rocha' pears from Location 2, at different dates of harvest (pick 1: $\diamond$; pick 2: $\square$; pick 3: $\triangle$ ), throughout time in the open air at room temperature, after storage for 4 (a), 6 (b) and 9 (c) mo in air (1), under $2 \%(\mathrm{v} / \mathrm{v}) \mathrm{O}_{2}+0.5 \%(\mathrm{v} / \mathrm{v}) \mathrm{CO}_{2}(2)$ and under $2.5 \%(\mathrm{v} / \mathrm{v})$ $\mathrm{O}_{2}+0.7 \%(\mathrm{v} / \mathrm{v}) \mathrm{CO}_{2}(3)$. Each datum represents the average of at least 15 experimental values, and bars represent the associated standard deviation; the lines represent the fitted model (depicted as Eq. (1), with estimated parameters as listed in Table 4).

\section{References}

Allen, F. W. (1939). Influence of carbon dioxide in lengthening the life of Bartlett pears. Proceedings of the American Society of Horticultural Science, 37, 473-478.

Avelar, M. L. (1984). Influence of picking date on the further behavior of 'Rocha' pear. Acta Horticulturae, 161, 25-29.

Galvis-Sánchez, A. C., Fonseca, S. C., Morais, A. M. M. B., \& Malcata, F. X. (2003). Physicochemical and sensory evaluation of 'Rocha' pear following controlled atmosphere storage. Journal of Food Science, 68(1), 318-327.

Hansen, E., \& Mellenthin, W. M. (1962). Factors influencing susceptibility of pears to carbon dioxide injury. Proceedings of the American Society of Horticultural Science, 80, 146-153.

Hansen, E., \& Mellenthin, W. M. (1979). Commercial handling and storage practices for winter pears. Oregon State University Agricultural Experimental Station No. 550. pp. 1-5.
Hansen, M. (1999). Pear storage regime can impact fruit quality. Good Fruit Grower. Available from: <www.goodfruit.com>.

Klahre, J., Mellenthin, W., Chen, P., Valentine, F., Talley, E., Bartram, R., \& Raese, T. (1987). D'Anjou harvest maturity and storage. Postharvest Pomology Newsletter, 5(2), 10 14.

Kupferman, E. (1987). Brown core, a disorder of CA stored pears. Postharvest Pomology Newsletter, 5(2), 15-17.

Kupferman, E. (1994). Anjou pear quality: fruit quality. Tree Fruit Postharvest Journal, 5(1), 3-10.

Kvåle, A. (1977). The effect of different harvest dates on shelf life and quality of 'Moltke' pears. Acta. Agriculturae Scandinavica, 27, 326330.

López, M. L., Miró, R., \& Graell, J. (2001). Quality and aroma production of Doyene du Comice pears in relation to harvest date and storage atmosphere. Food Science and Technology International, 7(6), 493-500. 
Meheriuk, M., Evans, C., Talley, E., \& Kupferman, E. (1988). Harvest maturity and storage regime for pears. Postharvest Pomology Newsletter, 6(3), 11-15.

Saltveit, M. E. (2003). Is it possible to find an optimal controlled atmosphere? Postharvest Biology and Technology, 27(1), 3-13.
Sharples, R. O., \& Johnson, D. S. (1987). Influence of agronomic and climatic factors on the response of apple fruit to controlled atmosphere storage. HortScience, 22(5), 763-766. 